\title{
The Effect of Bonyan-Method Experiential Marathon Structured Groups (BEMSG) on the Elements of the Five-Factor Model of Personality
}

\author{
Arash Nejatian ${ }^{1}$, Maryam Khaksar $^{2} \&$ Leila Azimi $^{3}$ \\ ${ }^{1}$ Department of psychology, Payame Noor University, Tehran, Iran \\ ${ }^{2}$ Allameh Tabataba'i University, Tehran, Iran \\ ${ }^{3}$ Behavioral Sciences Research Center, Shahid Beheshti University of Medical Sciences, Tehran, Iran \\ Correspondence: Arash Nejatian, Department of psychology, Payame Noor University, Tehran, Iran.
}

Received: July 6, 2021

Accepted: August 19, 2021

Online Published: August 23, 2021

doi:10.5539/ijps.v13n3p56

URL: https://doi.org/10.5539/ijps.v13n3p56

\begin{abstract}
Various studies have shown the effectiveness of marathon groups on improving participants' personality components. For the first time, the present study has studied the effectiveness of one of the oldest marathon groups in Iran on the personality elements of the Big Five model in the nonclinical population. This study was performed quasi-experimental with an experimental $(n=50)$ and a control group $(n=50)$. To meet the entry criteria, all applicants were screened while completing a comprehensive demographic questionnaire. The experimental group participated in the marathon group on three days in a row (for 36 hours) and three weekly follow-up sessions. At the end of the third follow-up session, the NEO FFI questionnaire was simultaneously given to the experimental and control groups. The mean difference statistical tests showed that the score of all personality elements in the experimental group compared to the control group had changed significantly $(\mathrm{P}<0.05)$. Among these, the largest effects size are related to "extraversion", "responsibility" and "openness to experience" ( $>0.4$ ), respectively. Individual and group constructive experiential games and intensive and sequential feedback processes in Bonyan-method experiential marathon groups seem to improve the Big 5 personality components in the nonclinical population. Considering the relationship between improving the components of personality and mental health, it can be predicted that important steps can be taken to promote the community's mental health and prevent psychological damage by using these groups.
\end{abstract}

Keywords: structured marathon groups, experiential group, personality, big five personality test, large experiential group, neo test

\section{Introduction}

\subsection{The Multi-Factor Model of Personality}

Personality is a complex research topic in psychology with a long history of changing philosophies and theories (Ackerman, 2017). Although it is easy to imagine personality daily, conducting credible scientific research on personality is very complex. Many personality theories have been developed to complement previous work. Therefore, a review of psychological studies on personality makes it easier to understand better the model of five personality factors.

The rationality of personality has a strong trace in the studies and theories of prominent contemporary psychologists. Sigmund Freud, known as the father of psychoanalysis, also focused on personality rationality, and some of his ideas are familiar to many. Freud's personality theory is based on three parts of the human mind: the id, ego, and superego. The id is the central part of the human mind that works on the principle of pleasure. The ego maintains the distance between the desires of the id and the realities of everyday experience and provides fundamental ways to achieve the wants and needs of the id. The superego is the mind that defines the highest human characteristics and the moral framework for regulating human behavior. This theory reflects that at least some of the thoughts, behaviors, and motivations are unconscious.

Other modern theorists who have theorized about personality include Carl Gustav Jung, Abraham Maslow, and Carl Rogers. Their work builds the foundation of the different theories, including the multi-factor model. The multi-factor model of personality is the product of the work and participation of many independent researchers. Gordon Allport and Henry Odbert first compiled a list of 4,500 personality trait terms in 1936 (Vinney, 2018), which provided the 
basis for other psychologists to study and explain the basic dimensions of personality. In the 1940s, Raymond Cattle reduced the Allport list to sixteen. However, other psychologists, including Donald Fiske, Norman, Smith, Goldberg, McCrae, and Costa, further explored the Cattle list and summarized it into five main attributes (Cherry, 2019).

Meanwhile, Lewis Goldberg specifically and strongly supported the five main personality factors (Ackerman, 2017). McCray and Costa expanded Goldberg's work. They first validated the model and then presented the model used today. The five main factors include the following elements: openness to experience, conscientiousness, extraversion, Agreeableness, and neuroticism.

This model became known as the "Big Five" and has received much attention. Much research has been done to confirm this model in different populations and cultures, and it is still accepted and used as one of the most widespread personality theories today. In this model, each of the five personality traits represents an extensive category that includes many terms related to personality. Each adjective contains many other aspects. For example, the adjective extraversion is a category that contains tags such as collectivism (association), expression and acknowledgment (with power), activity (energetic), seeking excitement (adventurer), positive emotions (enthusiasm), and warmth in association (Extrovert) (John and Srivatsova, 1999). Thus, the Big Five, although not entirely comprehensive, cover almost all personality terms. Another critical aspect of the "Big Five" model is its approach to measuring personality. In this model, the concepts related to attributes are seen as a spectrum and not black and white (Table 1). Studies have shown that most people are not at the polar end of the spectrum but somewhere in the middle of the range.

Table 1 . Features of the five personality characters

\begin{tabular}{|c|c|c|}
\hline Low score & Character traits & High score \\
\hline $\begin{array}{ll}\text { - } & \text { Practical } \\
\text { - } & \text { Conventional } \\
\text { - } & \text { Everyday preference } \\
\text { - } & \text { Impulsive } \\
\text { - } & \text { careless } \\
\text { - } & \text { messy } \\
\text { - } & \text { Silent } \\
\text { - } & \text { reserved } \\
\text { - } & \text { Unmotivated } \\
\text { - } & \text { Critical } \\
\text { - } & \text { Lack of cooperation } \\
\text { - } & \text { Suspicious } \\
\text { - } & \text { Calm } \\
\text { - } & \text { mild } \\
\text { - } & \text { With mental security }\end{array}$ & $\begin{array}{l}\text { Conscientiousness (C) } \\
\text { (Competence, self-discipline, thinking, } \\
\text { goal-oriented) } \\
\text { Extraversion (E) } \\
\text { (Socialization, expression, expression of } \\
\text { emotions) } \\
\text { Agreeableness (A) } \\
\text { (Participation, trustworthy, good mood) } \\
\text { Neuroticism (N) } \\
\text { (Tendency to unstable emotions) }\end{array}$ & $\begin{array}{ll}\text { - } & \text { curious } \\
\text { - } & \text { wide range of interests } \\
\text { - } & \text { Independent } \\
\text { - } & \text { hard worker } \\
\text { - } & \text { trustworthy } \\
\text { - } & \text { Organized } \\
\text { - } & \text { Express and acknowledge } \\
\text { - } & \text { Warm and extroverted } \\
\text { - } & \text { Looking for adventure } \\
\text { - } & \text { Helpful } \\
\text { - } & \text { Trust } \\
\text { - } & \text { Susceptible to negative emotions } \\
\text { - } & \text { Empathetic } \\
\text { - } & \text { Anxious } \\
\text { - } & \text { Dissatisfied }\end{array}$ \\
\hline
\end{tabular}

(Gray, 2017)

\subsection{The Impact of Marathon Groups for Improving the Status of the Mental Health and Personality}

Reviewing the scientific literature of psychology, it seems that improving the status of the components of personality and consequently individual and organizational growth is one of the goals pursued by different psychological approaches for nonclinical populations. These include intensive encounters and marathon groups. As the name implies, marathon groups refer to a long, continuous, and intensive process of group confrontation, which is held in a place-time of $18,24,36$, and 72 hours depending on the group's goals. The venue is a quiet and disturbing environment with minimal environmental stimuli. Although marathon groups are designed and organized in very different ways, the common feature of these groups is a close encounter with others focusing on the "here and now," meaning that what matters is the participants' momentary experience, whether it is a narrative experience. It is far from the past, whether it was created in the same group.

Marathon groups are divided into two types: unstructured and structured. Unstructured groups are confrontations between individuals without a predetermined plan and are entirely based on the experiences that occurred in the 
group. While in structured marathon groups, activities and processes are predetermined for each day, and each part of the program and individuals build their own experiences and those of the group within the framework of this structure (Weigel, 2002) (Bach, 1966) (Pothier, 1970) (Gottschalk, Pattison, \& Schafer, 1971).

Dinges \& Weigel, in their study on marathon group, review the works of Mintz (1971), Bach (1967), Demos (1970), Rachman (1969-1970), Rogers (1967, 1967), Yalom (1970), and other famous group treatment organizers. They have stated that marathon groups are among the most direct, efficient, and economical ways to prevent mental health damage, such as fragmentation (Note 1) and meaninglessness (Dinges \& Weigel, 1971).

\subsection{Bonyan-Method Experiential Marathon Structured Groups (BEMSG)}

Bonyan-Method Experiential Marathon Structured Groups (BEMSG) were founded in 1989 by Fereshteh Mirhashemi in the United States. It aims to transform \& grow the nonclinical population's personal and professional life (Mirhashemi, In Press). BEMSG groups are planned in intensive programs on the last three days of the week, which align with the common trend of marathon groups (Schaefer and Galinsky, 1989). BEMSG programs' sessions start with a brief on the method's basic principles, followed by the individual and group structured experiential process and games coupled with sequential feedback. This process will develop a dynamic space for participants' personal experiences to become aware of their own and others' cognitive, emotional, and behavioral patterns and habitual patterns known as a comfort zone. By acknowledging this awareness, a breakthrough experience will occur, and they discover their values.

Also, existential and acquired values and skills will be discovered, the space of possibilities will be opened, and the relationship with oneself, others, and the world will be established (Langar, 2014; Ghorbani, 1397; and Sanaei-Zakir, 1395) (Mirhashemi, 2021).

BEMSG is formed based on the Bonyan theory of being. Genealogically this theory is the family of existential psychology theories (May, Angel, \& Alnberger, 1994; Cooper, 2003). This theory focuses on "To Be with What It Is." This explanation of existence is based on the BE-DO-HAVE triangle and an open view of existence based on wholeness, integrity, and intentionality. The method, born of this theory, by choosing to be present here-and-now and being an observer on "How to Be With What It Is," while acceptance, responsibility, and commitment lead to the "effective \& productive state of being" (Mirhashemi, 2021).

Although BEMSG has a history of more than 30 years, no studies have been conducted on the effect of participating in these groups on individuals' personalities. Given the background on the effectiveness of participating in marathon groups on participants' psychological components, this article contains research results to answer whether BEMSG groups are influential based on Big Five personality characters.

\section{Method}

\subsection{Participants}

The number of participants in this study was 100, 50 were in the experimental group, and 50 were in the control group. To meet the criteria of the nonclinical population, all applicants were first screened. Standards such as age over 20, minimum bachelor's degree, employment, commitment to group rules, and informed consent to participate in the group were also considered for sample counterparts. The experimental group was evaluated for the variable after the end of the program. The control group was assessed in the same variable simultaneously as the first group without participating in the program.

\subsection{Research Tools}

The NEO FFI Personality Questionnaire was used for the present study, a personality questionnaire that examines a person's five major personality traits (experience openness, responsibility, extraversion, agreeability, and neuroticism). Historically, the development of a modified version of the Neo Test began in 1978 with the publication of the Character List by Costa and McCrae. In 1985, 1992, and 2005, the researchers published three updated versions of their personality questionnaire called the NEO PI, NEO PI-R (or revised NEO PI), and NEO PI-3, respectively. The questionnaires have two versions: long (total) and short. The full NEO PI-R contains 240 items and provides accurate partial scores, while the shorter NEO-FFI has only sixty items (12 per domain). This questionnaire was initially designed for adult men and women without overt psychopathology (McCrae, Costa, \& Martin, 2005).

For NEO FFI (60-question version) the internal consistency reported in the manual was: neuroticism $(\mathrm{N})=0.79$, extraversion $(E)=0.79$, openness to experience $(O)=0.80$, agreement $(A)=0.75$, Liability $(C)=0.83$. Sherry et al. reported the internal consistency of $\mathrm{FFI}$ as follows: $\mathrm{N}=.85, \mathrm{E}=.80, \mathrm{O}=.68, \mathrm{~A}=.75, \mathrm{C}=.83$. (Sherry, Hewitt, Flett, Lee-Baggley, \& Hall, 2007) 


\subsection{Procedure}

In this study, sampling was done as a convenience sampling method, and the design was quasi-experimental with an experimental $(\mathrm{n}=50)$ and a control group $(\mathrm{n}=50)$ with post-test. In the quasi-experimental design of two groups with the post-test and heterogeneous control group (Nonequivalent control group posttest-only design), the dependent variable is measured after the intervention and its amount between two unequal groups, namely experimental and control groups with similar characteristics and without random distribution, compared (Bhattacherjee, 2019), (Gravetter, 2009), (Frey, 2018). All participants in this study initially face a comprehensive demographic form (including demographic characteristics, educational and professional status, marital status, goals of group participation, history, and physical and mental health problems, possibly traumatic experiences in childhood) along with the knowledge of the group's regulations and the participation consent. They were then screened through an interview. The first fifty participants were assigned to the experimental group, and the remaining fifty were considered the control group.

The group was held on the last three days of the week (three 12-hour days, for a total of 36 hours), followed by three weekly follow-up sessions to monitor the group participants' experiences. The duration of the group was entirely in line with the standards of the marathon groups. The meetings were held in formal and nonclinical settings. Participants follow the main rules of the program, including attending the entire program, no use of drugs, stimulants, and alcohol for three days, and no smoking at the time and place of the program. They were committed to safekeeping the group's experiences and the conversations of others. The group stopped for 2 hours of breathing and lunch, but participants did not leave the program. After the third follow-up session, the NEO FFI questionnaire was given to the experimental and control groups.

\subsection{Statistical Analysis}

The two-group post-test design with the control group is a simpler version of the pre-test post-test design in which pre-test measurements are omitted (Gravetter, 2009). Shapiro-Wilk test $(\mathrm{P}<0.05)$ was used to evaluate the normality of data distribution of research variables (Bhattacherjee, 2019). If the hypothesis of normality was not established for either of the two groups, nonparametric tests such as the U Mann-Whitney test was used, which is the nonparametric equivalent of the independent $t$-test. To evaluate the effect of participating in the program on each of the big five personality factors, Pearson correlation statistics $r$ for nonparametric tests, and Cohen $d$ for parametric tests were used. (Mayers, 2013)

\section{Results}

The average age in the experimental group was 36.3 years. The youngest and oldest participants in the experimental group were 23 and 61 years old, respectively. The calculated standard deviation was 8.38 . The control group's mean age, minimum and maximum age and standard deviation were 35.2, 20, 53, and 7.97, respectively. For the nonparametric "age" data in both groups, the Mann-Whitney test showed that the two groups were not significantly different in terms of the age of participants. In both experimental and control groups, $70 \%$ of the sample size were women, and $30 \%$ were men.

Shapiro-Wilk test was used to evaluate the normality of data distribution of research variables. The distribution was normal in all the data specified in Table 2, except for "neuroticism" and "responsibility." The Mann-Whitney test was used for these two variables. In other cases, the independent $t$-test was applied to study the mean difference (more correctly, 'difference in means') in experimental and control groups. These are standard statistics that measures the absolute difference between the mean value in two groups. 
Table 2. Test of normal distribution of research data

\begin{tabular}{lllll}
\hline \multirow{2}{*}{ Personality factors } & \multirow{2}{*}{ Group } & \multicolumn{2}{l}{ Shapiro-Wilk } & \\
\cline { 2 - 4 } Neuroticism & Statistic & Df & Sig. \\
\hline \multirow{2}{*}{ Extroversion } & Control & .929 & 50 & .005 \\
& Experimental & .968 & 50 & .201 \\
Openness & Control & .978 & 50 & .453 \\
\multirow{2}{*}{ Agreeableness } & Experimental & .976 & 50 & .410 \\
\multirow{2}{*}{ Conscientiousness } & Control & .968 & 50 & .186 \\
& Experimental & .961 & 50 & .096 \\
& Control & .958 & 50 & .072 \\
& Experimental & .982 & 50 & .632 \\
& Control & .986 & 50 & .796 \\
& Experimental & .946 & 50 & .024 \\
\hline
\end{tabular}

*. This is a lower bound of the true significance.

a. Lilliefors Significance Correction

A summary of the test results is given in Table 3. All five factors in the experimental group showed significant growth compared to the control group.

Table 3. Summary of test results in experimental and control groups (difference in means)

\begin{tabular}{llllll}
\hline $\begin{array}{l}\text { Personality } \\
\text { factors }\end{array}$ & \multicolumn{2}{c}{ Average } & Test & p-values & effect size \\
\cline { 2 - 5 } & Experimental & Control & & & \\
\hline Neuroticism & 30.12 & 33.38 & Mann-Whitney U & $0.007^{*}$ & $r=-0.3$ \\
Extroversion & 36.80 & 32.56 & Independent-t & $0.000^{*}$ & $d=0.8$ \\
Openness & 41.74 & 40.02 & Independent-t & $0.043^{*}$ & $d=0.4$ \\
Agreeableness & 46.26 & 43.34 & Independent-t & $0.003^{*}$ & $d=0.6$ \\
Conscientiousness & 47.14 & 43.74 & Mann-Whitney U & $0.041^{*}$ & $r=0.2$
\end{tabular}

As shown in the table above, there is a significant difference between the control and experimental groups for all five personality elements. In all cases except neuropathy, the mean scores of the experimental group were higher than the control group. Although the changes and differences in the means were significant $(\mathrm{P}<0.05)$, as can be seen, the effect size of the personality elements was different. The largest effect size is related to "extraversion", "responsibility" and "openness to experience" ( $>0.4)$, respectively. This means that the mean scores of these personality elements in more than $80 \%$ of the control group are lower than the mean scores in the experimental group. In other words, participation in the program has significantly increased these factors in more than $80 \%$ of participants (McLeod, 2019). This value is between $69 \%$ and $79 \%$ in groups with average effect sizes, including the "neurotic" personality element. The smallest effect size was related to "agreeableness," where participants observed changes between $58 \%$ and $69 \%$.

\section{Discussion}

According to the results, it can be said that participating in BESMG has had a significant positive effect on all personality indicators of the "Big Five," which is in line with the existing background in this field. For example, a 1969 study by Mitchell showed the growth of personality components following participation in marathon courses (Mitchell, 1969).

Although all five personality elements in the experimental group were significantly different from the control group, the effect size was not the same among the indicators, and the highest impact was related to "extraversion," "responsibility," and "openness to experience," respectively. "Neuroticism" and "Agreeableness" were in the medium and low effect size groups, respectively.

These results are consistent with Sutherland's findings, which showed that participating in the marathon programs has different effects on participants than traditional group approaches due to the tight schedule in these groups 
(Sutherland, 1970). Participants in a marathon group also experience more cohesion, flexibility, intimacy, and empathy than their group experience (Dies \& Hess, 1970) and (Sutherland, 1970). In contrast, these individuals have less social presence and intellectual efficiency than participants in a non-marathon group experience (Sutherland, 1970).

Research results generally indicate that participating in a marathon group is always associated with experiencing negative emotions (such as anger) (Myerhoff, Jacobs, \& Stoller, 1970). In the present study, the extent and experience of negative emotions by participants has not been studied. However, it seems that such experiences are part of the nature of marathon programs. The participants' focus during the long duration of the program is on experiencing the "here and now." There is no other subject or topic that distracts the participants. These factors give the marathon program an intense and unavoidable feeling of being "under pressure" - like a pressure cooker. This feeling is a crucial concept in the process that helps a person overcome anger, defense, and social fears by using tiredness, coping, and hardship (instead of alcohol or drugs) and expose themselves to open disclosure and honest dealings with others (Bach, 1966) (Stoller, 1968a) (Stoller, 1968b).

As mentioned, the most significant effect sizes in this study were related to "extraversion," "responsibility," and "openness to experience." Extraversion indicates the tendency and intensity of individuals' desire to interact with their environment, especially the environment and social relations. Extraversion suggests the level of acceptance and level of comfort of people in social situations. In addition, it reflects the sources from which one draws energy (John \& Srivastava, 1999). Extroverts are generally assertive, sociable, fun-loving, and outgoing. They thrive in social situations and feel comfortable expressing their opinions. They tend to gain energy and get excited about being around others. Those who score low on extraversion are often referred to as introverts. These people tend to be more silent. They prefer to listen to others instead of being heard. To rejuvenate, introverts often need solitude because participating in social relationships can be very frustrating for them. It is important to note that introverts do not necessarily dislike social events but rather find them boring. (John \& Srivastava, 1999)

Responsibility describes a person's ability to regulate emotions to participate in purposeful behaviors. This trait measures elements such as control, inhibition, and stability of behavior (Grohol, 2019). Those with high scores of responsibilities can be described as organized, disciplined, thoughtful, and meticulous. They also have reasonable emotional control that allows them to perform their tasks and achieve goals. People with low responsibility scores may have difficulty controlling their emotions, making it difficult to do things and achieve goals. They tend to be erratic and may hate the structure too much. They may also engage in impulsive and reckless behaviors.

Openness to experience refers to a desire to try new things and do imaginary and intellectual activities. This includes the ability to "think outside the box" (John \& Srivastava, 1999). Those who score high on openness to experience are known as creative and artistic. They prefer diversity and independence. They are curious about their surroundings and enjoy traveling and learning new things. People who have a low score for being open to experience prefer the usual routine without change. They are not upset about changing and trying new things but prefer familiar things to unknown ones. Because they are pragmatic people, it is often difficult for them to think creatively or abstractly.

In the present study, "Agreeableness" showed the smallest effect size. However, it should not be forgotten that the rate of change of this index in the experimental group compared to the control group was significant. Agreeableness refers to how people treat their relationships with others. Unlike extroversion, which is about achieving relationships, Agreeableness focuses on the orientation and how people interact with others in the relationship itself (Ackerman, 2017). People with high levels of Agreeableness can be defined as compassionate, trustworthy, and loving. They are sensitive to the needs of others and reach out to others for help and cooperation. People consider them credible, reliable, and altruistic. In contrast, people with low levels of Agreeableness may be perceived as suspicious, deceitful, or uncooperative. They often empathize and oppose when interacting with others, making them less liked and trusted by others.

According to the results of Sutherland's research on the reduction of social presence and less mental efficiency of participants in marathon groups than participants in a non-marathon group experience (Sutherland, 1970), it is possible to link the reduction of the "Agreeableness" effect size to the time-consuming nature and marathon of such programs.

In general, it can be said that participating in these groups has had a positive effect on regulating relationships with oneself and others for participants. There is much research on the relationship between people's performance at work and their social relationships and mental health with the extent and growth of the five personality indicators. Thus, Meyer's research has shown that in marriages where one partner has less privilege in terms of personality elements of "conscientiousness," "responsibility," and "openness," there is likely to be marital dissatisfaction (Myers, 2011). 
Other research has shown that people with high "neuroticism" scores are particularly vulnerable to mood disorders such as depression. Low "conscientiousness" is also likely associated with other health problems (John \& Srivastava, 1999).

Individual and group constructive experience games and intensive and sequential feedback processes in BEMSG seem to improve the functions of the five personality elements in the nonclinical population. Also, focusing on "being in the moment" to cross the safe zone of habits directly affects personality elements such as openness to experience (Ackerman, 2017). Considering the relationship between improving the status of these personalities and mental health elements, it can be predicted that by implementing BEMSG programs, essential steps can be taken to promote society's mental health and prevent psychological damage.

Much of the work in this approach is to make people aware of the consequences of their resistance and defenses, leading to improved performance of personality elements in the Big five model of personality (Zandi, Shahabinejad, $\&$ Borhan, 2017). The present study also showed a significant change in this index.

Only the relationship and effectiveness of participating in BEMSG on the personality elements have been studied in the present study. Therefore, it is suggested that the mechanism of the program's effect on these five elements be studied as qualitative research. The amount and type of negative emotions experienced by participants and the process of their changes during the BEMSG program are also suggested as additional research.

\section{Acknowledgment}

Special thanks to Fereshteh Mirhashemi, who openly encouraged us to carry out this project. We thank Farshid Moradian for clarifying our theoretical views on the Bonyan-Method theory and method. We also appreciate all the help and support we received from Bonyan-Methods players through the various stages of this research.

\section{References}

Ackerman, C. (2017, June 23). Big Five Personality Traits: The OCEAN Model Explained. Retrieved from https://positivepsychology.com/big-five-personality-theory

Bach, G. (1966). The marathon group: Intensive practice of intimate interaction. Psychological Reports, 18(3), 995-1002. https://doi.org/10.2466/pr0.1966.18.3.995

Bhattacherjee, A. (2019). Social Science Research: Principles, Methods, and Practices. Retrieved from https://scholarcommons.usf.edu/oa_textbooks/3/

Bugental, J., \& Bracke, P. (1992). The future of existential-humanistic psychotherapy. Psychotherapy, 29, 28-33. https://doi.org/10.1037/0033-3204.29.1.28

Cherry, K. (2019, October 14). What Are the Big 5 Personality Traits? Retrieved from https://www.verywellmind.com/the-big-five-personalitydimensions-2795422

Dies, R. R., \& Hess, A. K. (1970). Self-Disclosure, Time Perspective and Semantic- Differential Changes: Marathon and Short-Term Group Psychotherapy. Comparative Group Studies, 1(4), 387-395. https://doi.org/10.1177/104649647000100406

Dinges, N., \& Weigel, R. (1971). The marathon group: A review of practice and research. Comparative Group Studies, 2(4), 339-458. https://doi.org/10.1177/104649647100200401

Frey, B. B. (2018). The SAGE Encyclopedia of Educational Reseach, Mesurment and Evalouation. https://doi.org/10.4135/9781506326139

Gottschalk, L., Pattison, E., \& Schafer, D. (1971). Training groups, encounter groups, sensitivity groups and group psychotherapy. California Medicine, 115(2), 87.

Gravetter, F. (2009). Research methods for the behavioral sciences (3rd ed). London: SAGE Publications, Inc.

Gray, R. M. (2017). The Importance of Personality Trait Screening for Today's Organizations - Application of the Five $\quad$ Factor Model (FFM). Retrieved https://sites.psu.edu/leadership/2017/09/02/the-importance-of-personality-trait-screening-for-todays-organizatio ns-application-of-the-five-factor-model-ffm/

Grohol, J. M. (2019, May 30). The Big Five Personality Traits. Retrieved from https://psychcentral.com/lib/the-big-five-personality-traits

John, O. P., \& Srivastava, S. (1999). The Big-Five trait taxonomy: History, measurement, and theoretical perspectives. In L. A. Pervin \& O. P. John (Eds.), Handbook of personality: Theory and research (Vol. 2) (pp. 102-138). New York: Guilford Press. 
Jung, C. G. (2009). Liber Novus ('The New Book'). New York: Philemon Foundation and W. W. Norton \& Co.

Lloyd, G. (1964). The Hot and the Cold, the Dry and the Wet in Greek Philosophy. The Journal of Hellenic Studies, 84, 92-106. https://doi.org/10.2307/627697

Mayers, A. (2013). Introduction to statistics and SPSS in Psychology. (A. Rezaee, Trans.) Pearson.

McCrae, R. R., Costa, P. T., \& Martin, T. A. (2005). The NEO PI-3: A more readable revised NEO personality inventory. Journal of Personality Assessment, 84(3), 261-270. https://doi.org/10.1207/s15327752jpa8403_05

McLeod, S. A. (2007). Social psychology. Retrieved from https://www.simplypsychology.org/social-psychology.html

McLeod, S. A. (2019). Simply psycology. Retrieved from https://www.simplypsychology.org/effect-size.html

Mirhashemi, F. (2021). Abundance. Tehran: Chiman.

Mitchell, R. R. (1969). An evaluation of the relative effectiveness of spaced, massed and combined sensitivity training groups in promoting positive behavior change. Los Angeles: University of California.

Myerhoff, H. L., Jacobs, A., \& Stoller, F. H. (1970). Emotionality in marathon and traditional psychotherapy groups. Psychotherapy: Theory, Research and Practice, 7(1), 33-36. https://doi.org/10.1037/h0086547

Myers, D. G. (2011). Psychology (10th ed.). Worth Publishers.

Neal, A., Yeo, G., Koy, A., \& Xiao, T. (2012). Predicting the form and direction of work role performance from the Big 5 model of the personality trait. Journal of Organizational Behavior, 33(2), 175-192. https://doi.org/10.1002/job.742

Pothier, P. (1970). Marathon Encounter Groups: Rationale, Techniques, and Crucial Issues. Perspectives in psychiatric care, 8(4), 153-159. https://doi.org/10.1111/j.1744-6163.1970.tb01318.x

Schneider, K. (2016). Existential-integrative therapy: Foundational implications for integrative practice. Journal of Psychotherapy Integration, 26(1), 49. https://doi.org/10.1037/a0039632

Sherry, S. B., Hewitt, P. L., Flett, G. L., Lee-Baggley, D. L., \& Hall, P. A. (2007). Trait perfectionism and perfectionistic self-presentation in personality pathology. Personality and Individual Differences, 42(3), 477-490. https://doi.org/10.1016/j.paid.2006.07.026

Sutherland, S. H. (1970). A study of the effects of a marathon and a traditional encounter group experience. Unpublished research manuscript. Lubbock: Texas Tech University.

Veronica, G. T., \& Patricia, B. C. (2020). Evaluation in Today's World FIRST EDITION: Respecting Diversity, Improving Quality, and Promoting Usability. SAGE Publications, Inc.

Vinney, C. (2018, September 27). Understanding the Big Five Personality Traits. Retrieved from https://www.thoughtco.com/big-fivepersonality-traits-4176097

Weigel, R. (2002). The marathon encounter group--vision and reality: Exhuming the body for a last look. Consulting Psychology Journal: Practice and Research, 54(3), 186. https://doi.org/10.1037/1061-4087.54.3.186

Zandi, S., Shahabinejad, Z., \& Borhan, A. (2017). Predicting defense mechanisms based on big five personality traits among university students. Zanko Medical Journal, 21-32.

\section{Note}

Note 1. Fragmentation of memory is a memory disorder in when an individual is unable to associate the context of the memories to their autobiographical (episodic) memory.

\section{Copyrights}

Copyright for this article is retained by the author(s), with first publication rights granted to the journal.

This is an open-access article distributed under the terms and conditions of the Creative Commons Attribution license (http://creativecommons.org/licenses/by/4.0/). 